\title{
Memórias étnicas e comunitárias entre lideranças femininas do Sapê do Norte - ES
}

\author{
Ethnic and community memories among female leaders \\ in Sapê do Norte - ES
}

\author{
Pedro Henrique Barbosa de Souza \\ Mariana Bonomo \\ Universidade Federal do Espírito Santo \\ Brasil
}

\begin{abstract}
Resumo
A partir da perspectiva psicossocial da memória social, o estudo teve como objetivo analisar as memórias étnicas e comunitárias entre mulheres quilombolas, líderes de uma comunidade localizada na região do Sapê do Norte - ES. Utilizando um roteiro semiestruturado, foram entrevistadas seis mulheres, com idades entre 32 e 65 anos. As narrativas foram sistematizadas por meio da análise de conteúdo, a partir de três unidades temáticas: memórias e vivência das mulheres, aspectos do cotidiano e identidade. Os resultados indicaram que as atividades religiosas, culturais, de trabalho, lazer e as formas de cuidado com a saúde possuem relação com a ancestralidade e com o território. A partir da memória oral e da memória prática, as memórias pessoais se confundem com a história do grupo, mesmo que as pessoas não tenham vivido determinados fatos históricos e sociais diretamente, configurando importante campo de significação que orienta os processos de identificação social na comunidade.
\end{abstract}

Palavras-chave: identidade social; memória social; mulher quilombola; psicologia social; quilombo.

\begin{abstract}
Stemming from the psychosocial perspective of social memory, the study aimed to analyze ethnic or community memories among quilombola women, leaders of a quilombola community located in the region of Sapê do Norte ES. Using a semi-structured script as reference, six women were interviewed, aged between 32 and 65 years old. The narratives were systematized through content analysis, based on three main thematic units: memories and life experiences of women in the community; aspects of daily life; and identity. The results indicated that religious, cultural, work and leisure activities, as well as health care, are related to ancestry and to the territory. From oral and practical memory, personal memories become confused with the group's own history, even if people have not experienced certain historical and social facts directly, configuring an important field of meaning that guides the processes of social identification in the community.
\end{abstract}

Keywords: social identity; social memory; quilombola women; Social Psychology; quilombo. 


\section{Introdução}

Os registros documentais e historiográficos apontam que durante o século XIX foram constantes as fugas e as formações de quilombos no território de Sapê do Norte, estado do Espírito Santo (Oliveira, 2016). E foi durante o período escravista e colonial que se originaram as comunidades quilombolas que vivem até hoje nessa região. Essas comunidades viviam em suas terras abundantes em recursos naturais e vegetação nativa, com suas práticas tradicionais e seu modo de vida característico até meados do século $X X$, momento em que o capital agroindustrial, principalmente de empresas que utilizam o sistema de plantation de eucalipto, de cana de açúcar e de café, se instalou e passou a explorar os recursos naturais e a expropriar o território dos quilombolas do Sapê do Norte (Ferreira, 2010).

A participação das mulheres quilombolas na organização comunitária e em movimentos políticos de defesa do território tem sido abordada em diversos estudos (Bragas \& Cal, 2019; Costa, 2018; Rodrigues, 2016; Silva, 2015; Siqueira, 2017). Bragas e Cal (2018) alertam, contudo, que o papel da mulher ficou mais complexo a partir das lutas de reconhecimento do território, uma vez que, simultaneamente, passaram a ser responsáveis pela liderança política da comunidade, bem como pelas tarefas domésticas e comunitárias. Sobre essa dimensão, Riscado, Oliveira e Brito (2010) destacaram o aspecto da saúde na vivência cotidiana e na construção identitária das mulheres quilombolas, que têm em seu imaginário a demarcação dos papéis destinados ao cuidado da casa e da família, como atividades feminizadas e de atribuição à mulher.

O aspecto da interseccionalidade entre raça, gênero e geração foi abordado nos estudos de Grossi, Oliveira e Oliveira (2018) e de Bragas e Cal (2018), que destacaram as diversas violações de direito vivenciadas por essas mulheres, tais como: dificuldade de acesso a políticas públicas; insegurança alimentar; não valorização do saber dos conhecimentos ancestrais e da identidade étnico-racial; dificuldade de se inserir no mercado de trabalho; machismo que se materializa nas mulheres casadas que querem estudar, mas acabam sendo proibidas pelos maridos; bem como luta pela titulação do território.

Alinhada a essa perspectiva de análise interseccional, Rodrigues (2016) se propôs a descrever os processos de construção, recriação e expressão das identidades sociais e políticas, assim como evidenciar os processos de afirmação cultural que se tornam demarcadores identitários dos quilombolas, como a prática do jongo, as brincadeiras, as festas e as devoções aos santos padroeiros de comunidades. Costa (2018) reforça essa proposição reflexiva ao argumentar 
que essa análise auxilia a pensar as trajetórias das mulheres quilombolas, posto que essas categorias (gênero, raça e geração) se refletem nas práticas, investimentos e no modo de agir cotidiano, bem como na elaboração da história de vida dessas mulheres, como guardiãs das memórias e tradições, entendias aqui como a posição de narradora das histórias da família e da comunidade (Caixeta, 2006), Bosi (1979) complementa que esta função está relacionada a velhice social, sendo que tais elementos constituem e fundamentam a identidade étnica da comunidade.

\section{O campo de estudo psicossocial da memória social}

A memória vem sendo objeto de estudo e de investigação em diferentes domínios do conhecimento, como nas produções artísticas, filosóficas e políticas, e também nas diversas áreas da ciência (Bosi, 2003; Jedlowski, 2003; Sá, 2007; 2016). São relativamente recentes os estudos sobre memória social na Psicologia Social, embora a obra inicial da área sobre o tema se encontre nos anos de 1930, com o estudo de Bartllet (1932/1995). Nas últimas décadas, contudo, é que se inicia uma série de estudos que sistematizam uma Psicologia Social da memória social (Sá, 2007; 2013; 2016), inspirados, principalmente, nos desdobramentos das proposições pioneiras do sociólogo Halbwachs (1925/1994) e de Bartllet (1932/1995), bem como em releituras modernas de Jedlowski (2003) e, em menor escala, também nas ideias do psicólogo russo Vygotsky (Sá, 2013).

Essa proposta psicossocial de reconstrução teórico-conceitual da memória social a entende como uma rede complexa de atividades, em que o passado nunca permanece como tal e qual, mas é selecionado e reestruturado diante das necessidades do presente (Jedlowski, 2003). Nesse sentido, Sá (2007) desenvolve três orientações para o estudo da Psicologia Social da Memória Social: (1) a primeira destaca que ela deve ser entendida como fenômeno multifacetado e que possui diversas adjetivações e manifestações; (2) a segunda fundamentase em cinco pressupostos ou princípios, quais sejam, (i) as informações são selecionadas e reestruturadas a partir de interrogações e necessidades do presente, (ii) a memória é social, histórica e culturalmente condicionada, mas é preciso ressaltar que é o sujeito que se lembra; (iii) estão na dependência das interações e comunicações sociais; (iv) pensamento e memória sociais estão intrinsicamente associados e são praticamente indistinguíveis; e (v) a emoção, o afeto e a motivação desempenham papel importante na construção da memória social; e (3) na terceira orientação, por sua vez, são evidenciadas as diversas instâncias da memória social, conforme mapeamento das memórias da memória social realizado por Sá (2007). 
Por meio do mapeamento, desenvolvido por Sá (2007; 2013; 2016), foi possível sistematizar as instâncias da memória social em dois grupos principais: (1) memórias básicas, que seriam que se refere aos tipos de interação no processo de construção da memória; e (2) memórias mais complexas, na quais estão contidas as memórias mais frequentes e circunstanciadas (Sá, 2016).

O primeiro grupo é composto por dois subconjuntos de diferentes âmbitos ou alcance do processo de construção social da memória. No primeiro subconjunto estão contidas as memórias pessoais, que falam sobre o passado da pessoa que é construída com outras pessoas; as memórias coletivas, definida por Jedlowiski (2003, p. 211) como "Conjunto de representações sociais que tem a ver com o passado produzido por cada grupo, institucionalizado, guardado e transmitido pela interação de seus membros"; e as memórias comuns, entendidas como coleções de memórias pessoais sobre o mesmo objeto (Sá. 2013, 2016).

O segundo subconjunto de memórias básicas, servem como suportes da construção da memória, nela estão contidas as memórias orais, que são aquelas que não possuem fontes documentais; as memórias documentais, "que tem por base registros materiais ou documentos que incluem as mais variadas inscrições, como livros, museus, monumentos, mídias, etc." (Sá, 2013, p. 17); e por fim, as memórias práticas, que são estão incorporadas nos hábitos e nas performances coletivas (Sá, 2013; 2016).

No que se refere ao segundo conjunto de memórias mais complexas, este se constitui pelas seguintes categorias de memória: testemunhais, autobiográficas, étnicas ou comunitárias, populacionais, institucionais, históricas ou de fatos históricos, e públicas (Sá, 2013; 2016).

Nesse estudo, como referencial para a análise do fenômeno identidade no contexto comunitário quilombola, utiliza-se as memórias comunitárias ou étnica, posto que a principal função da memória é favorecer a coesão de um determinado grupo, bem como garantir a sua identidade (Bonomo, 2010; Deschamps \& Moliner, 2008; Halbwachs, 1994; Turner, 1984). Pollak (1992) também articula memória social e identidade, propondo que a memória é constituída por três elementos, a saber, os acontecimentos, as pessoas ou personagens, e os lugares conhecidos diretamente ou por "tabela", ao se tratar de uma projeção em outros eventos mesmo que as pessoas não os tenham vivido diretamente.

A instância das memórias étnicas e comunitárias refere-se a memórias construídas no âmbito do grupo que mantém contato direto (face a face) e contínuo entre si, como, por exemplo, comunidades religiosas, colônias de imigrantes e comunidades tradicionais (Sá, 2013). Por mais variados que sejam 
os contextos e interesses de cada grupo, o que se encontra na base de tais instâncias é o empenho dos seus membros na produção, conservação e transmissão das memórias coletivas, que podem se subordinar às memórias pessoais, e, até mesmo, transformar algumas delas em memórias comuns em determinada dimensão geracional. Dependendo do grau de organização de cada grupo, além de memórias orais e memórias práticas, podem ser mobilizadas, de forma específica, algumas memórias documentais (Sá, 2013; 2016).

Considerando tais apontamentos, o estudo teve como objetivo analisar as memórias étnicas ou comunitárias entre mulheres quilombolas, líderes de uma comunidade quilombola localizada na região do Sapê do Norte - ES, a partir da perspectiva psicossocial da memória social.

\section{Método}

Participaram deste estudo seis mulheres de uma comunidade do Sapê do Norte - ES, com idades entre 32 e 65 anos. Foram convidadas a participar do estudo, mulheres consideradas lideranças comunitárias que foram indicadas pelos próprios moradores. Neste sentido, é importante salientar que os resultados apresentados nesse estudo não representam toda a comunidade ou todas as mulheres quilombolas, mas sim a trajetória de um grupo de mulheres que são referências comunitárias em diferentes aspectos no quilombo em questão.

O instrumento para coleta dos dados consistiu em um roteiro de entrevistas semiestruturado, ou seja, criamos um roteiro prévio composto de perguntas abertas e fechadas, que nos orientaram durante a realização da entrevista. No entanto, não nos prendemos de modo rígido à estrutura elaborada e fomos flexíveis de acordo com cada contexto abordado no desenrolar das entrevistas com as participantes (Flick, 2013). As questões elaboradas tiveram como objetivo apreender informações sobre a história de vida das entrevistadas, a história da comunidade, aspectos do cotidiano e sobre ser mulher quilombola. As entrevistas foram gravadas e transcritas posteriormente.

Os dados obtidos foram organizados a partir da análise de conteúdo temática/categorial, conforme proposta por Bardin (2004), e sistematizada por Oliveira (2008). Tal análise consiste em um conjunto de técnicas que, por meio de procedimentos objetivos, tem como tarefa final a descrição e interpretações do texto (Bardin, 2004).

A análise foi organizada em três etapas, sendo elas: 1) a pré-análise - fase de organização do material e sistematização das ideias iniciais; 2) a exploração do material - que é a fase de análise propriamente dita e que consiste em 
codificar o material, ou seja, transformar os dados brutos em unidades de registros, que, no caso deste trabalho, se trata do conteúdo temático contido nas narrativas das participantes; e 3) o tratamento dos dados - fase em que os resultados foram tratados e interpretados, resultando na elaboração de categorias temáticas em consonância com o fenômeno em análise (Bardin, 2004; Oliveira, 2008). Seguindo as orientações de Oliveira (2008), para esta análise, os conteúdos dos textos foram transformados em unidades de registro (UR), que deram origens a eixos temáticos, que, por sua vez, agregaram temas e subtemas. Junto às categorias temáticas (temas e subtemas), são apresentadas as frequências absolutas correspondentes (identificadas por $\mathrm{f}$ ).

Informamos, ainda, que todos os procedimentos éticos para desenvolvimento de pesquisas com seres humanos foram seguidos e que esse estudo foi aprovado pelo Comitê de Ética em Pesquisa, da Universidade Federal do Espírito Santo, sob parecer n. CAAE 19403519.7.0000.5542.

\section{Resultados}

O presente estudo é fruto de parte dos resultados da dissertação de mestrado do primeiro autor, sob a orientação da coautora. A inserção do autor na comunidade se deu através do Grupo de Capoeira Angola Volta ao Mundo (Vitória - ES), que desenvolve trabalhos no território quilombola do Sapê do Norte, desde o ano de 2017, juntamente com agricultores quilombolas que organizam o CSA Sapê do Norte (Consumidores que Sustentam a Agricultura). O território do Sapê do Norte compreende áreas dos municípios de São Mateus e de Conceição da Barra no norte do estado do Espírito Santo, e atualmente, tem 29 comunidades quilombolas reconhecidas pela Fundação Cultural Palmares $(\mathrm{FCP})^{1}$.

A comunidade em que o estudo foi desenvolvido está localizada na área rural de uma das cidades que compõem a região do Sapê Norte - ES, e está relativamente próxima a área urbana do município. A rodovia que dá acesso à comunidade está sendo asfaltada e, em seu entorno, notamos uma extensa área de monocultivo de eucalipto, com pequenos blocos de vegetação nativa. Em pequenas áreas agricultáveis, entre os longos plantios de eucaliptos das chamadas grandes empresas, os moradores da comunidade vivem em seus núcleos familiares, cultivando a terra e as suas tradições.

1 Informações mais detalhadas sobre a certificação quilombola podem ser encontradas em http://www.palmares.gov.br/?page id=37551. 
Iniciamos a descrição dos resultados apresentando o território, assim como as mulheres que participaram do estudo, que são lideranças no quilombo do Sapê do Norte - ES. A fim de garantir o sigilo e o anonimato, foram dados nomes fictícios às participantes.

A primeira quilombola com quem tivemos contato foi Dona Zacimba, reconhecida como a mulher que puxa as discussões sobre a regularização fundiária e como a guardiã da memória da comunidade, que conhece as histórias dos antepassados que viveram no território. Além disso, ela é agricultora, pescadora, faz beiju, é zeladora da Santa na mesa de Santa Bárbara, benzedeira, brincante de jongo e de reis de bois, bem como referência de seu núcleo familiar.

Dona Constância é outra guardiã da memória da comunidade, zeladora da Santa na mesa de Santa Bárbara e, além disso, é a responsável por fazer a comida a ser ofertada aos Santos. Também é benzedeira e uma profunda conhecedora do uso dos "matos" para fins medicinais, e, quando se tem dúvida sobre as questões espirituais e de saúde, na maioria das vezes, procura-se Constância para solucioná-las. Foi brincante de Reis de Bois, brincadeira que herdou de seu pai, que foi mestre de reis por muitos anos. Ela é ainda pescadora, catadora de caranguejo, agricultora e "senhora do dendê", ou seja, uma das mulheres que produz o azeite de dendê, e referência em seu núcleo familiar.

Acotirene é agricultora e é a mais velha entre as entrevistadas e uma das moradoras mais antigas da comunidade. Portanto, é sempre uma referência entre os demais moradores, como uma das pessoas que detém o conhecimento das práticas tradicionais da comunidade e como quem conviveu com muitos dos seus antepassados. Acotirene é devota da igreja católica e uma das pessoas mais ativas nas missas, rezas e cultos familiares junto com sua filha.

Tereza é a filha mais nova de Dona Constância, trabalha como professora na comunidade e é uma das lideranças mais jovens da comunidade. Uma de suas funções é guardar e organizar os documentos da regularização fundiária do território, e, além disso, ela representa a comunidade e sempre está falando sobre a luta dos moradores em espaços fora do território, como congressos, seminários e encontros acadêmicos. Ela foi uma das pessoas que resgatou o jongo numa época em que ele era bastante escasso na comunidade e não havia o interesse dos mais novos. Além disso, foi uma das responsáveis pela organização da associação do grupo jongo.

Dandara é a irmã mais nova de Dona Zacimba, trabalha como agente de saúde na comunidade. Ela é uma das coordenadoras da Igreja Católica, sempre está participando das questões logísticas da organização da igreja, é uma das pessoas que limpa a igreja no dia anterior à reza e é responsável por verificar se têm velas, hinários, cadeiras e outros materiais necessários para a liturgia da 
missa. Ela está sempre com Dona Zacimba nas discussões políticas e na luta pela conquista do território e, além disso, é brincante do jongo e participa de apresentações e viagens junto com o grupo Jongo de Santa Bárbara.

Luíza tem 42 anos e é referência no núcleo familiar em que vive. Sua mãe, Dona Nanã, é a moradora mais velha da comunidade e Luíza é a filha mais próxima. Portanto, é responsável por auxiliá-la no seu cotidiano. Além disso, ela é agricultora, pescadora e é militante na luta pelo território, estando sempre envolvida nos debates e discussões sobre a regularização fundiária do quilombo.

A análise das narrativas das participantes permitiu a identificação de importantes temáticas para a reflexão e debate sobre os fenômenos de identidade no contexto quilombola. Na Tabela 1, é descrita a síntese do conteúdo analisado a partir das entrevistas realizadas com as participantes, organizado em três eixos temáticos, cada um desses eixos com temas e subtemas específicos.

Tabela 1. Eixo temático e Temas

\begin{tabular}{|c|c|c|}
\hline Eixo Temático & Temas & Descrição do Tema \\
\hline \multirow{2}{*}{$\begin{array}{l}\text { I - Memórias e } \\
\text { Vivência das } \\
\text { Mulheres da } \\
\text { Comunidade }\end{array}$} & $\begin{array}{l}\text { História do Território } \\
\text { e da comunidade }\end{array}$ & $\begin{array}{l}\text { Neste tema estão presentes os relatos das } \\
\text { memórias e histórias da comunidade e do território. }\end{array}$ \\
\hline & $\begin{array}{l}\text { Trajetória de vida das } \\
\text { mulheres quilombolas }\end{array}$ & $\begin{array}{l}\text { Relatos e descrições das memórias relacionadas à } \\
\text { história de vida pessoal e da família das } \\
\text { entrevistadas. }\end{array}$ \\
\hline \multirow{5}{*}{$\begin{array}{l}\text { II - Aspectos do } \\
\text { Cotidiano }\end{array}$} & Trabalho & $\begin{array}{l}\text { Este tema integra todos os relatos e descrições das } \\
\text { atividades de trabalho remuneradas ou não, } \\
\text { mencionados pelas participantes. }\end{array}$ \\
\hline & Educação & $\begin{array}{l}\text { Este tema abrange os relatos e descrições das } \\
\text { atividades formais e informais de educação } \\
\text { vivenciadas pelas mulheres da comunidade. }\end{array}$ \\
\hline & Cultura/Lazer & $\begin{array}{l}\text { O conteúdo desse tema diz respeito aos relatos e } \\
\text { descrições de atividades relacionadas à cultura e ao } \\
\text { lazer, conforme entrevistadas. }\end{array}$ \\
\hline & Religiosidade & $\begin{array}{l}\text { O tema é referente às crenças e práticas da fé das } \\
\text { participantes, bem como os aspectos litúrgicos dos } \\
\text { rituais das organizações religiosas relatados por } \\
\text { elas. }\end{array}$ \\
\hline & Saúde & $\begin{array}{l}\text { Este tema abrange os conteúdos relacionados à } \\
\text { forma como as mulheres lidam com a saúde. }\end{array}$ \\
\hline \multirow{2}{*}{$\begin{array}{l}\text { III - Pertencimento } \\
\text { identitário }\end{array}$} & Ser Quilombola & $\begin{array}{l}\text { Relatos de como foi o processo de auto- } \\
\text { reconhecimento como quilombola. }\end{array}$ \\
\hline & $\begin{array}{l}\text { Ser Mulher } \\
\text { Quilombola }\end{array}$ & $\begin{array}{l}\text { Relatos sobre as especificidades de ser mulher } \\
\text { quilombola. }\end{array}$ \\
\hline
\end{tabular}

No primeiro eixo temático foram agrupadas as memórias contadas sobre a comunidade e o território. Para esse agrupamento, elaboramos os temas História da Comunidade e do Território e Trajetória de Vida das Mulheres Quilombolas (Ver Tabela 2). 
Tabela 2. Temas e subtemas do Eixo Temático "Memória e Vivências das Mulheres da Comunidade"

\begin{tabular}{|c|c|c|c|}
\hline Temas & Subtemas & $\mathrm{f}$ & Exemplos de fragmentos da subcategoria no texto \\
\hline \multirow{3}{*}{$\begin{array}{l}\text { História da } \\
\text { comunidade } \\
\text { e do } \\
\text { território }\end{array}$} & $\begin{array}{l}\text { Tempo dos } \\
\text { antigos }\end{array}$ & 10 & $\begin{array}{l}\text { "Que mandava no Brasil e era eles que mandava negro, } \\
\text { trazia negro, era os branco que trazia, matava, matava } \\
\text { não falava índio, mas eles matava muitos caboclos e aí } \\
\text { quando a família real, esses pessoal português chegou } \\
\text { aqui, já existia muita gente aqui dos nossos... aí eles } \\
\text { foram lá e trouxeram mais negros pra trabalhar com } \\
\text { eles, com a Rita Cunha, com Antônia Pinheiro, Antônia } \\
\text { Pinheiro era irmã de Rita Cunha"2. }\end{array}$ \\
\hline & $\begin{array}{l}\text { Antes da } \\
\text { chegada da } \\
\text { empresa }\end{array}$ & 18 & $\begin{array}{l}\text { "Aqui era do meu pai, ali, naquele eucalipto ali, era um } \\
\text { campo onde eles botavam uma égua branca que eles } \\
\text { tinham, tinha a roça pra lá, pra lá tinha roça. Esse } \\
\text { eucalipto todinho aí tinha um campo de um animal. Esse } \\
\text { aí que era pra ser meu, com meus filho tudo". }\end{array}$ \\
\hline & $\begin{array}{l}\text { Depois da } \\
\text { Chegada da } \\
\text { empresa }\end{array}$ & 9 & $\begin{array}{l}\text { "O córrego secou, isso aí foi na época do eucalipto e lá } \\
\text { em cima quando a gente vai pra braço do rio tinha uma } \\
\text { nascente, depois que plantou eucalipto secou, secou. Ai } \\
\text { ficou aí essas águas preta, todo mundo, a gente fazia } \\
\text { tudo no córrego, era ali que passava ali". }\end{array}$ \\
\hline \multirow{2}{*}{$\begin{array}{l}\text { Trajetória de } \\
\text { vida das } \\
\text { Mulheres } \\
\text { quilombolas }\end{array}$} & Relatos sobre si & 8 & $\begin{array}{l}\text { "É, aí eu tinha que fazer concurso, alguma coisa pra eu } \\
\text { poder passar, pra eu poder sustentar minhas duas } \\
\text { filhas... aí que eu fui fazer esse concurso que o meu } \\
\text { primo chamou. Eu fiz, eu passei, eu nem tava na espera } \\
\text { que eu ia passar também, ai fiquei na prefeitura. E } \\
\text { Zacimba trabalhava no colégio também, me ajudava } \\
\text { muito também". }\end{array}$ \\
\hline & $\begin{array}{l}\text { Parentesco e } \\
\text { rede familiar }\end{array}$ & 10 & $\begin{array}{l}\text { "Ai ela [mãe] juntou com ele [pai] aqui quando ela tinha } \\
\text { treze anos, aí ela fala meu pai é daqui, porque o sogro } \\
\text { dela falava que nunca era pra ela sair dessa terra, } \\
\text { porque essa terra era dela, porque cuidava dele em cima } \\
\text { da cama doente". }\end{array}$ \\
\hline
\end{tabular}

Quanto à história da comunidade e do território, notamos que existem três momentos distintos relatados. O primeiro deles, por nós denominado Tempo dos Antigos ( $f=10)$, remete às histórias das pessoas que viveram naquela região no período escravagista. É possível observar que parte do conhecimento e das histórias deste período foi contada através da oralidade pelos "veios" (pais, avós e bisavós das entrevistadas) quando ainda estavam vivos. Também notamos que essas memórias estão presentes na fala da geração mais velha das entrevistadas, como Acotirene (64 anos) e Constância (62 anos), mas principalmente de Zacimba (59 anos), esta última considerada uma espécie de guardiã das histórias da comunidade.

Ela [Tia de Acotirene] explicava lá desde os negócios dos quilombolas. Agora é Zacimba que sabe tudinho, ela sabe. Que era

\footnotetext{
${ }^{2}$ Rita Cunha e Antônia Pinheiro eram lideranças políticas escravagistas e donas de terras no Norte do Estado do Espírito Santo no Século XIX e negociaram com "Negro Rugério".
} 
quilombola, a bisavó dela, a avó dela era quilombola mesmo, diz que é da família da minha avó, a minha tia falava (Acotirene).

Sobre a comunidade notamos que os nomes dos sítios e locais dentro do território receberam os nomes de núcleos durante a criação do RTID (Relatório Técnico de Identificação e Demarcação) para facilitar a comunicação com agentes externos; no entanto, foi contado que, antigamente, esses locais eram chamados por outros nomes, em geral, eram identificados pelo nome dos rios, córregos e famílias que moravam no local. Estes nomes ainda estão presentes no vocabulário dos mais velhos, porém, os mais jovens utilizam o termo núcleo familiar.

A história da formação do quilombo é contada a partir de quando os brancos chegaram naquela região (durante o período escravista), e foi explicado que já havia negros e caboclos (indígenas) morando ali antes deles chegarem. Os brancos trouxeram junto com eles negros escravizados de outras regiões para trabalhar: "esses pessoal português chegou aqui, já existia muita gente aqui dos nossos, aí eles foram lá e trouxeram mais negros pra trabalhar com eles" (Zacimba).

Nomes como de Rita Cunha (uma fazendeira escravista da região), Antônia Pinheiro (irmã de Rita Cunha) e Barão de Aimorés, são lembrados pelos quilombolas como fazendeiros escravistas que ali viveram. Elas nos contam que os negros daquela época negociavam e tinham relações comerciais com os brancos. Destaca-se, por exemplo, Negro Rugério, que foi o fundador do quilombo, criado a partir de um acordo com Rita Cunha, no qual ele se comprometeu a produzir farinha de mandioca em troca de terra. Podemos perceber que a terra naquela época era usada como moeda de troca, pagamentos, doações e negociações:

... meu bisavô, tatáravô, ele recebeu uma doação em 1909 da irmã de Rita Cunha, doação de terra, tinha o documento aí no cartório, tem puxado tudo no cartório, eles trabalhava pra eles e recebia (Zacimba).

Além de Negro Rugério, foram citados os negros Benedito Meia-Légua, Zacimba Gaba, Viriato Cancão de Fogo, Amélia, Constância de Angola e Olinda como pessoas que viveram e lutaram pela sobrevivência do quilombo. Os moradores da comunidade possuem conhecimento sobre características, grau de parentesco, atividades que realizavam e local onde moravam os antepassados do quilombo, ainda do período escravista, através do relato dos antigos: 
... vovó tinha um pedaço de café perto do córrego do lado de lá, que o filho da Olinda, que é uma escrava que gostava do Jongo, que eles falava, ela ficava do lado de cá do córrego (Zacimba).

O segundo momento relatado sobre a história da comunidade, nomeamos como Antes da Chegada da Empresa $(\mathrm{f}=18)$, em que estão agrupados os relatos de como era o funcionamento da comunidade a partir da desagregação das fazendas escravistas que produziam farinha, até a chegada de fazendeiros e empresas de monocultivo na região durante as décadas de 1960 e 1970. Dentre as entrevistadas, Tereza (35 anos) não vivenciou esse período, no entanto, relata histórias que foram contadas pelos mais velhos, bem como alguns processos de mudanças decorrentes da expropriação do território.

... não cheguei a pegar essa época, eu conheço só pelas histórias que elas contam que aqui tinha muito córrego, muito rio e que hoje tá tudo aí, dentro da área da empresa (Tereza).

Através do relato das mulheres quilombolas, pode-se perceber que a comunidade vivia de maneira harmoniosa, utilizando os recursos naturais do território para criar suas famílias, trabalhar, se divertir e extrair o alimento da natureza e do cultivo da terra.

Era uma coisa que não faltava nada, graças a Deus, e agora é uma coisa que você não pode, você não pode dar uma pescada, não pode caçar, você não pode ir no mangue, você não pode fazer nada disso hoje em dia não. A gente fazia isso e não tinha nada que empatava a gente não (Constância).

A chegada de fazendeiros e empresas monocultoras na comunidade, durante as décadas de 1960 e 1970, marcou a fala das mulheres. Nesse período, se iniciou, primeiramente, a plantação de cana de açúcar e, posteriormente, a extensa plantação de eucalipto que ocupa o território atualmente. A partir desse momento, foram destruídas as matas nativas com os "correntões" (dois tratores amarrados entre si com correntes), e passou a ter um fluxo migratório muito grande dos moradores, principalmente para centros urbanos.

Quando a empresa chegou aqui, eles metia as correntes. Tinha trator pra arrancar isso aqui, era dois trator acorrentado com um correntão e entrava na mata assim e ia levando tudo, quebrando tudo, não deixava nada em pé não. Ia puxando e arrastando com os trator, um de lá e outro de cá com um correntão no meio e ia quebrando tudo, as matas, os pau, lenha, ia embora tudo... aí plantou esse troço aí (Constância). 
O último momento que destacamos na narrativa das entrevistadas sobre a história da comunidade remete às consequências sofridas pelo território e seus moradores a partir da chegada das empresas e fazendeiros na região. Nomeamos esse subtema como Depois da chegada da empresa ( $\mathrm{f}=9$ ). Observamos que os relatos trazem a experiência da escassez dos recursos naturais (principalmente, a água), que antes eram abundantes.

... [as mais velhas] contam que tinha muito, mas muito córrego mesmo, e nós que moramos aqui dentro da comunidade, a gente vê que é verdade porque a gente vê que se a gente andar aí no meio dos eucalipto, você vê o lugar que antes era e que hoje tá todo coberto de eucalipto. Secou as nascentes, elas tão totalmente seca, que é também uma problemática da nossa comunidade que é a falta de água (Tereza).

O segundo tema desse primeiro eixo é referente à história das entrevistadas, que nomeamos de Trajetória de vida das Mulheres Quilombolas, relativo aos relatos da trajetória pessoal das entrevistadas e sua história familiar.

Sobre os relatos que se referem às trajetórias de vida das entrevistadas, criamos o subtema Relatos sobre si $(\mathrm{f}=8)$. Nota-se que, em geral, elas contam sobre a sua "vida sofrida", principalmente, com a falta de recursos financeiros e a dificuldade de acesso a direitos como território, educação, emprego e serviços de saúde. No entanto, apesar dessas dificuldades e através de muita luta, trabalho e cooperação dos outros quilombolas, eles conseguiram sustentar sua família e criar seus filhos: "Ai agora vou fazer vinte anos de prefeitura ano que vem já, mas foi um sofrimento na vida pra criar minhas meninas pra chegar até hoje aí" (Dandara).

Por fim, no subtema que nomeamos de Parentesco e Rede Familiar $(\mathrm{f}=10)$, foram agrupados os relatos sobre a história de suas famílias, tanto da família nuclear (composta, geralmente, por elas, seus companheiros e filhos), como a família da qual elas descendem e de quem herdaram o território. Observamos através das falas das mulheres que, de certa maneira, todas as famílias do quilombo possuem uma relação de parentesco sanguíneo:

É tia dela [de Zacimba] e o pai dela é tio meu, é tio meu, é irmão da minha mãe e minha mãe era irmã dele. Todo mundo é parente aqui, todo mundo! A avó de Tereza que é tia nossa (Acotirene).

O eixo temático II Aspectos do Cotidiano se refere à rotina e ao modo de vida na comunidade. Em seus relatos, elas falaram sobre as formas de trabalho, o processo de escolarização, a cultura e o lazer, bem como sobre saúde e religiosidade. É possível perceber que as atividades relatadas pelas mulheres 
indicam um modo de vida típico e que remetem à ancestralidade e a uma relação profunda com o território (Tabela 3).

No tema Trabalho, identificamos os relatos e as descrições das atividades laborais realizadas na comunidade. Observamos que todas as mulheres entrevistadas trabalham ou já trabalharam na roça. Atualmente, apenas Dandara e Tereza não são agricultoras, sendo as duas funcionárias públicas do município em que vivem (atuam, respectivamente, como agente de saúde e professora).

A partir do relato das entrevistadas, podemos verificar que o sustento das famílias se baseia em atividades que dependem dos recursos naturais do território, como árvores, mangue, terra, rios, lagoas e córregos. O trabalho da agricultura $(f=15)$ e a fabricação de alimentos $(f=8)$, que envolvem a produção de farinha de mandioca, beiju e dendê, assim como a pesca/mangue $(f=3)$, dependem de tais recursos e variam de acordo com o clima do território. É preciso destacar, contudo, que desde a chegada dos fazendeiros e empresas de monocultivo de eucalipto na região, nos anos sessenta, os moradores da comunidade encontram dificuldades para realizar tais atividades, como podemos verificar no relato de Constância:

A gente fazia isso [pescava, caçava] e não tinha nada que empatava a gente não. A gente saia e fazia mesmo, não importava se tava passando gente, a gente tava pescando, tava no mangue. Não tinha nada pra empatar o serviço da gente não, mas agora, com IBAMA aí, com as empresas, essa firma aí de fora aí, não deixa não. Corre atrás, corre atrás mesmo (Constância).

As relações de trabalho passaram a ser diferentes depois da chegada das empresas de monocultivo que expropriaram o território quilombola e plantaram eucalipto por quase todo o território. O desemprego $(f=4)$ passou a ser tema de preocupação na comunidade, principalmente, para a população mais jovem, o que levou à migração de muita gente para centros urbanos em busca de trabalho. No caso das entrevistadas Luíza e Dandara, quando jovens, elas tiveram que sair da comunidade e viver na área urbana da cidade local para trabalharem (Trabalho fora da comunidade $-\mathrm{f}=5$ ).

Como forma de sustento, surgiu uma nova fonte de renda entre os moradores, a partir da coleta de resíduos de eucalipto para produção de carvão, atividade popularmente conhecida entre os quilombolas como facho $(f=5)$. Houve, no entanto, um conflito entre a empresa e os moradores das comunidades quilombolas do Sapê do Norte em relação à atividade de coleta de facho. A disputa ocorreu, pois era proibida a entrada de moradores nas áreas de plantio de eucalipto, mas os quilombolas alcançaram da justiça o direito de coletar o 
Tabela 3. Temas e subtemas do eixo aspectos do cotidiano

\begin{tabular}{|c|c|c|c|}
\hline Tema & Subtemas & f & Exemplos de fragmentos da subcategoria no texto \\
\hline \multirow[b]{2}{*}{ Educação } & $\begin{array}{l}\text { Educação } \\
\text { Formal }\end{array}$ & 8 & $\begin{array}{l}\text { "A gente ia chegava lá e se arrumava todo... não é nada de bom, hein? Ia até de camisola pra escola, sacolinha de arroz (risos), } \\
\text { os caderno dentro. Não tinha serviço igual hoje ai... eu ia pra lá estudar". }\end{array}$ \\
\hline & $\begin{array}{l}\text { Educação } \\
\text { Informal }\end{array}$ & 3 & $\begin{array}{l}\text { "Mamãe não sabia não... foi aprender ler, tirar título, aprender ler, fazer o nome dela depois de nós, porque nós ensinava, nós } \\
\text { aprendia e ensinava a ler um pouco. Meu pai já sabia, João Cosme ele lia, ele lia, ele escrevia. A família do Cosme aprendeu } \\
\text { porque, eu falo que eles tiveram que aprender a fazer o nome pra tirar título pra poder votar". }\end{array}$ \\
\hline \multirow[t]{2}{*}{ Religiosidade } & $\begin{array}{l}\text { Mesa de } \\
\text { Santa } \\
\text { Bárbara/ } \\
\text { Cabula }\end{array}$ & 6 & $\begin{array}{l}\text { "... minha mãe é que rezava muito, a reza africana. Então, rezava muito mesmo. Chegava, assim, dia de quarta-feira de cinzas, } \\
\text { era fechado. Ah, era sábado de aleluia, aí ia lá e abria... era aquela reza bonita, a reza africana era muito bonita, viu?" }\end{array}$ \\
\hline & Igreja Católica & 5 & $\begin{array}{l}\text { "É, a comunidade mesmo [que organiza o culto], tem as equipes direitinho, equipe de fulano, equipe de beltrano e vai embora e } \\
\text { cada domingo tem o culto de alguma pessoa e vai trocando". }\end{array}$ \\
\hline \multirow{2}{*}{ Cultura/ Lazer } & Festas & 5 & $\begin{array}{l}\text { "Tinha muita festa! Agora parou um pouco, parou, tinha muita festa, tinha festa pra caramba... dava festa aqui pra caramba, } \\
\text { agora acabou, mas que tinha festa, tinha e era festa mesmo, virava a noite, a noite!". }\end{array}$ \\
\hline & Brincadeiras & 1 & $\begin{array}{l}\text { "Ave Maria, ele falava que ele tava de inxum, pregava mentira, que tava de caboclo, corria atrás dessas meninas, que tava de } \\
\text { Exu ... ai mas era uma alegria muito grande!". }\end{array}$ \\
\hline \multirow[b]{2}{*}{ Saúde } & $\begin{array}{l}\text { Medicina } \\
\text { popular }\end{array}$ & 12 & "Tomei remédio, tomei chá daqui, chá dali e fiquei bem graças a Deus". \\
\hline & $\begin{array}{l}\text { Medicina } \\
\text { convencional }\end{array}$ & 4 & $\begin{array}{l}\text { "Ela foi e mandou a mensagem pra mim: arranjei um médico, você quer ir pra ver se eles marcam a sua cirurgia? Eu falei: eu } \\
\text { quero. Aí foram cinco anos indo pra Vitória, saia daqui meia noite em risco de morrer pelas estradas no carro da saúde, pra cima } \\
\text { e pra baixo". }\end{array}$ \\
\hline \multirow{7}{*}{ Trabalho } & Agricultura & 15 & $\begin{array}{l}\text { "A vida toda só na enxada, na foice, limpando, lugar que tinha o sapê, porque aqui tinha mato o sapê, cavando sapê, baixando } \\
\text { pra botar suas roças, capinando... às vezes, se cortasse um pé de capoeirazinha, mas ali ele botava uma roça duas vezes, } \\
\text { depois eles deixava descansar, eles iam e botava mais pra frente pra terra descansar, pra terra produzir mato". }\end{array}$ \\
\hline & $\begin{array}{l}\text { Fabricação de } \\
\text { alimentos }\end{array}$ & 8 & $\begin{array}{l}\text { "As pessoas trabalham dentro do seu núcleo fazendo sua farinha, plantando sua mandioca, fazendo seu dendê, fazendo seu } \\
\text { beiju, mas não é suficiente para sustentar uma família, sustentar uma casa". }\end{array}$ \\
\hline & $\begin{array}{l}\text { Trabalho } \\
\text { Doméstico }\end{array}$ & 7 & $\begin{array}{l}\text { "... aí fico mexendo por aqui dentro de casa mesmo, fazendo as coisinhas, passo roupa, capino na beirada da casa, porque nasce } \\
\text { uns capinzinho perto de casa, aí eu vou capinando...". }\end{array}$ \\
\hline & Facho/ Carvão & 5 & $\begin{array}{l}\text { "Aí foi indo e tamo nessa luta até hoje e sofrimento e trabalhando nesse facho mesmo... é mais sofrimento ainda porque } \\
\text { arregaçou com a vida da gente, mas não tem outra coisa pra fazer, quem não tem mandioca, farinha e nada, né?". }\end{array}$ \\
\hline & $\begin{array}{l}\text { Trabalho fora } \\
\text { da } \\
\text { comunidade }\end{array}$ & 5 & $\begin{array}{l}\text { "[Na cidade] Eu trabalhava um mês para ganhar quinhentos e doze reais, com três crianças dentro de casa, pra pagar aluguel. } \\
\text { Eu fazia faxina, trabalhava pra outra pessoa, trabalhava de jardineiro, fazia um monte de coisa pra poder juntar dinheiro e ainda } \\
\text { pagar aluguel". }\end{array}$ \\
\hline & Desemprego & 4 & "Não tem trabalho pra jovem e ele acaba saindo da comunidade, muitos voltam, mas muitos acabam ficando na cidade". \\
\hline & Pesca/Mangue & 3 & "É pescaria, pescar, ir no mangue... era a vida nossa, né? O que era antigamente... a gente fazia, agora a gente não faz mais". \\
\hline
\end{tabular}


facho, desde que os trabalhadores estivessem cadastrados. Atualmente, essa atividade é uma das que mais gera renda na comunidade.

Aí foi indo e tamo nessa luta até hoje... e sofrimento e trabalhando nesse facho mesmo. É mais sofrimento ainda porque arregaçou com a vida da gente, mas não tem outra coisa pra fazer, quem não tem mandioca, farinha e nada, né? (Luíza).

Outra questão observada nos relatos das mulheres é que além de participarem das atividades mencionadas, todas relatam ter que realizar trabalhos domésticos $(\mathrm{f}=7)$, que consistem em limpar, lavar, passar roupa, cozinhar, etc. Tais atividades fazem parte da rotina diária de trabalho das mulheres quilombolas da comunidade.

O tema Educação foi dividido em dois subtemas. No primeiro deles, estão presentes os conteúdos referentes à educação formal $(f=8)$, destacada, principalmente, pelas entrevistadas mais novas (Luíza, Tereza e Dandara). A comunidade possui apenas uma escola, que oferece o ensino fundamental do 10 ao $5^{\circ}$ ano, sendo que as demais séries escolares podem ser cursadas apenas na área urbana do município. Dentre as entrevistadas, apenas Dandara e Tereza completaram a escolarização até o ensino médio, e também são as únicas que, atualmente, não possuem sua renda principal com o trabalho da agricultura. As duas são funcionárias públicas do município, sendo que Tereza possui ensino superior completo em pedagogia e é professora da escola da comunidade, enquanto Dandara é concursada como agente na área da saúde há vinte anos.

Sobre a educação informal $(f=3)$, Zacimba lembra que foi ela e seus irmãos que alfabetizaram a sua mãe. Para além da alfabetização, nesse tema, vemos a educação voltada para a formação política no qual se destacam os trabalhos de base, realizados nas igrejas e escolas com as crianças.

Isso tá errado e nós tão preparando essas crianças: lá dentro da escola, prepara; na escola, na reza nos núcleos familiares; pela bíblia, nós sentava, nós discutia, porque o evangelho, quando você vai ler ele, se você lê, só no amém vai ficar no amém... (Zacimba).

Outro tema desse eixo temático, nomeamos de Religiosidade, em que estão contidos os relatos sobre o funcionamento e rituais da igreja católica $(f=5)$, bem como sobre a Cabula e a Mesa de Santa Bárbara $(f=6)$. Sobre a Igreja Católica, foi explicado que ela está sob a responsabilidade da paróquia do município vizinho, e, um sábado por mês, ela envia o padre à comunidade para realizar a missa. As demais atividades da igreja ficam sob responsabilidade dos próprios quilombolas, que organizam a "reza" aos domingos e, durante os dias 
de semana, os encontros familiares. A reza dominical é organizada por equipes que ficam responsáveis pela liturgia, pela Homilia e pela limpeza da igreja.

Quanto à Cabula, foi explicado que se trata de uma religião de matriz africana que acontecia com frequência na comunidade antigamente, mas que hoje não é mais praticada devido à falta de conhecimento das rezas, ladainhas africanas e cantigas que os antigos sabiam e que foram se perdendo com o passar do tempo. No entanto, ainda hoje é mantido o ritual de lavagem da Santa, que acontece uma vez por ano durante a Semana Santa. Dentre as entrevistadas, Constância e Zacimba são responsáveis por esse ritual junto com suas primas.

A Cabula consiste em um conjunto de três mesas, segundo as participantes: 1) Mesa de Santa Bárbara, ritual que acontecia com maior frequência na comunidade, na qual as entidades chamadas de nagôres se manifestavam durante as rezas das ladainhas africanas e que eram guiadas pelo tambor do jongo; 2) Mesa de Santa Maria, que acontecia no meio da mata, em que se usava apenas as palmas, onde se manifestavam as entidades dos "caboclos", que era o povo que vivia no quilombo antes dos negros chegarem; e 3) Mesa de São Cosme e Damião, que acontecia apenas no mês de setembro e era dedicado às crianças.

Nas memórias relatadas, principalmente, sobre a mesa de Santa Bárbara, elas contam que os nagôres e os caboclos eram espíritos dos antepassados que viveram na região e que voltavam para ajudar os quilombolas. Eles ensinavam remédios, tiravam os olhados, benziam e curavam quem precisasse. As mulheres nos contaram que, por anos, a igreja católica perseguiu as religiões de matrizes africanas e que, por isso, o povo teve que disfarçar. Citam, por exemplo, que Santa Bárbara na verdade era Iansã e que usavam esse nome para enganar os brancos que perseguiam os rituais da Cabula.

No tema Cultura/Lazer são abordadas as brincadeiras $(f=1)$ e as festas $(f=5)$. Nota-se que os dois subtemas têm relação com a religiosidade, como, por exemplo, no relato de Zacimba, que contava que seu pai brincava com as crianças falando que havia recebido exus ou caboclos (entidades de religiões de matrizes africanas). Com relação às festas, percebemos que existem, pelo menos, dois tipos: a primeira relacionada às comemorações religiosas e a segunda a aspectos do trabalho. Nas festas religiosas, destaca-se o dia 4 de dezembro, que é dia de Santa Bárbara, a padroeira da comunidade. As entrevistadas ainda contam que essa festa estava relacionada também com as "ladainhas africanas" e com o "tambor", que faziam parte do ritual da Mesa de Santa Bárbara; porém, atualmente, o dia da Santa é comemorado apenas com uma missa. 
O tambor é uma referência ao jongo, que, segundo Zacimba, "eles fazia a rodada, aí entrava o jongo, fazia a rodada de jongo, porque o jongo vem do tambor, o culto africano vem do tambor dos nagôres". Com o passar do tempo, assim como a Mesa de Santa Bárbara, o jongo foi perdendo espaço na comunidade e só recentemente foi resgatado pelas gerações mais novas do grupo.

Assim, tinha um grupo (de jongo) mais antigo, né? Mas aí, foi se perdendo, né? Ai, minha geração formou um grupo de dança de jongo..., mas aí, já passou esse grupo pra outra geração que tá ai na comunidade, uma geração mais nova (Tereza).

Outra data comemorativa religiosa destacada pelas entrevistadas é o dia de Santo Reis, que acontece no dia 6 de janeiro. Nesse dia, acontecia a manifestação cultural do Reis de Bois, que é um cortejo com pessoas vestidas de animais, juntamente com uma orquestra dirigida por um regente que cantava as músicas e ia visitando as casas dos moradores de várias comunidades. Atualmente, os mais novos da comunidade e de comunidades vizinhas ainda brincam de reis; no entanto, as moradoras mais antigas se queixam de que não é feito como antigamente.

Era!! De ano em ano... aí ficava bonito, ensaiava o ano inteiro pra depois representar. Era uma semana de representação até no dia de Santo Reis, enterrava o boi no dia de Santo Reis, já enterrava na sua casa, cantava aí chegava no dia de Santo Reis, você enterrava ele na sua casa! Agora não, agora é reis todo dia, todo dia sábado e domingo tá passando, o que é isso? É reis que vai cantar no vilarejo, gente (Constância).

Já em relação às comemorações que celebravam algum aspecto do trabalho, destacamos a festa para comemorar a colheita, o dia de embarreio ${ }^{3}$ e o festival do beiju. As comemorações pela colheita e pelo dia de embarreio da casa são memórias dos mais antigos que contam sobre as festividades que marcavam o fechamento de um ciclo de trabalho, enquanto o festival do beiju é uma festa criada recentemente, entre as comunidades quilombolas do Sapê do Norte, a fim de valorizar e rememorar a cultura da produção do beiju. Todas as festas são regadas à sanfona, harmonia e diversão.

Em relação à dimensão saúde, as entrevistadas falaram a respeito da medicina convencional $(f=4)$ e da medicina popular $(f=12)$. Sobre o primeiro recurso, em que foi relatado sobre o acesso e o uso dos serviços de saúde no grupo, observamos que na comunidade existe uma agente de saúde (Dandara)

\footnotetext{
3 As casas eram feitas de estuque (pau-a-pique) e o embarreio era o momento em que se construía as paredes da casa com barro.
} 
que acompanha os moradores, principalmente, idosos, diabéticos e acamados. Notamos que quando é necessário utilizar algum serviço de maior complexidade, é necessário se deslocar a centros urbanos.

$\mathrm{Na}$ medicina popular se fazem presentes os elementos da ancestralidade, espiritualidade e territorialidade. É relatado que, com a chegada das empresas e fazendeiros na comunidade, "os mato", que são remédios caseiros feitos de plantas nativas e que são ensinados pelos mais velhos, ficaram escassos: "[O Guarandi] Dá nas mata, nos brejo... esses córrego todinho tinha. Agora cê procura um e não acha e era um remédio bom" (Constância). Conforme relato de Zacimba, os nagôres também ensinavam remédios para os quilombolas.

Que eles [os nagôres] usava o dendê, [...] ... era um grande remédio, né? Eles chamava de epô e abadô, os nagôs chamava assim. Aí eles fazia de lá o ritual e todo mundo lá dançando e criança e tudo dançava, né? Na casa, e eles benzia e dava remédio.

Todos os elementos relatados nesse eixo temático remetem a um modo de vida característico de se viver com significados que materializam a ancestralidade, a espiritualidade e a territorialidade quilombolas.

Por fim, o terceiro eixo temático foi chamado de Pertencimento identitário. Nele, estão os discursos referentes aos processos de identificação das participantes sobre Ser Quilombola e sobre Ser Mulher Quilombola (Ver Tabela 4).

Tabela 4. Temas e Subtemas do Eixo Temático "Pertencimento Identitário"

\begin{tabular}{|c|c|c|c|}
\hline Tema & Subtema & $f$ & Exemplos de fragmentos \\
\hline & Ser reconhecido & 8 & $\begin{array}{l}\text { "No meu talão de energia já vem Luíza da } \\
\text { comunidade quilombola. Eu sou até cadastrada } \\
\text { na tarifa social". }\end{array}$ \\
\hline $\begin{array}{c}\text { Ser } \\
\text { quilombola }\end{array}$ & Se reconhecer & 5 & $\begin{array}{l}\text { "quilombola é isso que viva no interior morando, } \\
\text { trabalhando, nasceu ali as mães da gente } \\
\text { nasceu ali, pai nasceu, mãe nasceu, o vô nasceu } \\
\text { e a gente também veio, também naquela luta, } \\
\text { naquela luta, trabalhando junto com eles ali } \\
\text { lutando". }\end{array}$ \\
\hline $\begin{array}{l}\text { Ser Mulher } \\
\text { quilombola }\end{array}$ & $\begin{array}{l}\text { Protagonismo } \\
\text { feminino }\end{array}$ & 4 & $\begin{array}{l}\text { "Tô junto com eles na luta como as outras } \\
\text { mulheres daqui também tão... homens e } \\
\text { mulheres, mas os homens, quando não quer, } \\
\text { nós mesmo vão (risos), as mulheres daqui não } \\
\text { tem isso não". }\end{array}$ \\
\hline
\end{tabular}

O tema Ser Quilombola foi divido em dois subtemas distintos. O primeiro, nomeamos de Ser reconhecido $(f=8)$, no qual foram agrupadas falas que abordam o reconhecimento da identidade quilombola por agentes externos da comunidade, motivados por um processo político. 
Não, não sabia o que era quilombo, eu mesmo não sabia, não sabia o que era quilombo não. Isso começou na época do Lula, que a gente começou a descobrir essas coisas, que as coisas começou a andar (Constância).

O segundo subtema nomeamos de "Se reconhecer" $(f=5)$, onde agrupamos as falas em que as entrevistadas reconhecem a si mesmas como quilombolas, relacionando com o território e com a história dos negros escravizados e seus descendentes.

É porque nós somos daqui e nós negros somos daqui e temos os nossos avós que foram pegado de cachorro, viu? Sob do africano, eu me entendo que é! Eu sou quilombola, eu me entendo, pelo sofrimento que a gente passa sem serviço, sem emprego (Luíza).

As mulheres afirmam, no entanto, que desde sempre souberam que são quilombolas, por causa das histórias que os mais velhos contavam, pelo modo de vida típico que levavam, pelos nomes dos lugares, por conta de objetos antigos que encontravam dentro da comunidade e também devido à comunicação a partir dos nagôres que se manifestavam na mesa de Santa Bárbara.

A gente já sabia a história, pelo engenho, pelo povo meu do engenho, pelo povo meu da colina, pelos cachimbo que eles fumava... o nosso pessoal dos nagôres, nós somos das família dos nagôres. O que é isso de nagôres lá do outro lado do rio, nosso pessoal, eles têm possibilidade quando eles morrer, eles vive é de reza (Zacimba).

Notamos que, apesar disso, também foi a partir do contato com agentes externos e da criação de políticas públicas que reconhecem os direitos de comunidades quilombolas, que elas passaram a se reconhecer como tal. Apesar do estímulo dos agentes externos, o reconhecimento como comunidade quilombola só se concretiza, contudo, com participação dos próprios quilombolas e com os conhecimentos ancestrais.

Isso aqui era passado e casaram e passaram pros filhos, netos tudo dessa maneira. Aí nós fizemos o reconhecimento da comunidade como quilombo, primeiro nosso relatório foi da Koinonia. Quem foi fazer foi as próprias meninas do quilombo, as próprias descendentes do quilombo que foi entrevistar o nosso pessoal antepassado... os nossos pais e nossas mães, ainda pegou eles todinho (Zacimba).

Foi possível notar na fala das entrevistadas que o pertencimento e a ligação com o território são demarcadores da identidade quilombola. Atualmente, o território da comunidade se encontra com o processo de titulação do território 
parado nas instâncias federais. Já foi feito o RTID e demarcados, aproximadamente, 3500 hectares de terra como pertencentes à comunidade. A titulação desse território é a garantia do direito de os moradores exercerem a sua identidade através do seu modo de vida e essa tem sido a principal luta das mulheres: "os negro precisa, as comunidades precisa do seu território demarcado e titulado e é isso que eu bato, não só hoje, mas toda vida, eu quero o que é nosso direito!" (Zacimba).

No segundo tema desse eixo temático, denominamos Ser Mulher Quilombola. Agrupamos nesse subeixo temático as falas que mostram o protagonismo e a liderança feminina $(f=4)$. Principalmente nas organizações políticas pela luta e conquista do território, as mulheres da comunidade são as referências, apesar do apoio dos homens. Contaram que nem sempre os homens estão presentes nas reuniões e inteirados sobre o assunto, diferentemente das mulheres, que conseguiram se organizar em uma associação e que estão sempre presentes e assumindo os papéis de liderança nesse contexto.

E também, né, também o grupo de mulheres dentro da comunidade, o grupo de mulheres é forte dentro das comunidades. O que eu vejo é que as mulheres que puxam o movimento. Os homens contribuem, mas de cabeça, de frente mesmo, é as mulheres, que tá sempre aí na luta, que tá sempre correndo atrás (Tereza).

A partir da descrição dos principais eixos temáticos identificados nas narrativas das participantes desse estudo, foi possível conhecer alguns dos elementos que compõem o universo de significados e práticas associados à identidade quilombola entre lideranças femininas de uma comunidade quilombola do Sapê do Norte-ES.

\section{Discussão}

Neste trabalho, buscamos analisar os processos identitários entre as mulheres quilombolas a partir da instância das memórias étnicas, numa perspectiva psicossocial da memória social. As memórias étnicas ou comunitárias, conforme Sá (2013), caracterizam-se pelo empenho de seus membros na produção, conservação e transmissão das memórias coletivas, que, dependendo do grau de coesão do grupo, tornam-se memórias pessoais ou mesmo memórias comuns, organizadas através das memórias orais e práticas.

Entendendo que a identidade é um processo em que os indivíduos atribuem significados afetivo-emocionais a seu pertencimento a diferentes grupos sociais, podemos refletir sobre as múltiplas possibilidades identitárias para os sujeitos, 
que podem assumir diferentes identidades de acordo com os grupos sociais aos quais se sentem pertencer (Turner, 1984). Nesse processo, os conceitos que envolvem a memória social são recursos analíticos indispensáveis para se refletir a respeito da construção do sentimento de continuidade, de uma pessoa ou grupo, na construção de si (Pollak, 1992) e na manutenção da coesão grupal (Jedlowiski, 2003).

Verificamos que as narrativas mais pessoais entre as entrevistadas são construídas a partir da memória coletiva do grupo, possibilitando a construção de um discurso de pertencimento a essa comunidade quilombola (Sá 2007; 2013; 2016). Ou seja, o passado rememorado na história de vida individual de cada entrevistada se mistura com os fatos sociais e históricos construídos coletivamente (Sá, 2016). Nesse contexto, a coesão entre os discursos das mulheres pode ser percebida nas memórias comuns, formadas mesmo quando as pessoas não são expostas ao mesmo fato (Sá, 2007; 2013; 2016), como, por exemplo, a geração mais nova (Luísa, Dandara e Tereza) que relata sobre a fartura do território antes da chegada da empresa, apesar de não ter vivenciado esse período.

No que se refere às memórias das mulheres na comunidade, foi possível verificar, ainda, a construção de uma memória coletiva sobre seus ancestrais, que resistiram ao sistema colonial escravista e que deixaram de herança o território em que vivem e o modo de vida característico da comunidade (Pollak, 1992; Bosi, 2003; Jedlowiski, 2003; Sá, 2007, 2013; 2016). Apresenta-se, também, a memória coletiva sobre a chegada de fazendeiros e empresários agroindustriais naquela região (a partir da segunda metade do século $X X$ ), que passaram a expropriar o território quilombola para o plantio de monocultivo de eucalipto com fins comerciais, destruindo a vegetação nativa e os recursos naturais. As memórias pessoais das mulheres sobre esse período são de violência, expropriação, dificuldade e escassez de recursos materiais, construídas a partir da ideia de uma "vida sofrida", posto que essa invasão alterou o seu cotidiano e o modo de vida que levavam no território (Oliveira, 2011; Ferreira, 2010; Silva, 2012).

Um dos princípios do estudo psicossocial da memória social é que a reconstrução do passado existe em função das necessidades e interesses do presente (Halbwachs, 1925/1994; Bartler, 1932/1995; Jedlowiski, 2003; Sá, 2007). Essa ideia pode ser complementada com a afirmação de Bosi (2003), de que a memória transmite em palavras uma experiência vivida, na qual se torna possível acessar momentos do passado que permanecem e justificam alguns comportamentos e práticas presentes. Nas narrativas das mulheres quilombolas, 
entendemos que relembrar coletivamente faz parte do processo de se aquilombar, ou seja, assumir a identidade de quilombola, a partir dos elementos sociais, religiosos e da saúde (Rabinovich, 2008) que se tornou para elas força, ou uma estratégia política para superar a "vida sofrida" (Pollak, 1992; Jedlowiski, 2003; Rabinovich, 2008).

Diante disso, notamos memórias práticas, que se referem às memórias que estão incorporadas nos hábitos e habilidades físicas pessoais, assim como nos rituais coletivos e nas comemorações (Sá, 2007; 2013; 2016), presentes no cotidiano das mulheres em seus fazeres, saberes e hábitos vivenciados em suas rotinas e modos de vida. Foi possível verificar que as atividades religiosas, culturais, de trabalho e de lazer, bem como as formas de cuidado com a saúde possuem relação com a ancestralidade e com o território.

Nesse sentido, entendemos que as atividades de trabalho (como a agricultura e a produção de beiju e azeite de dendê), as práticas educativas, as brincadeiras dos "reis de boi", a batida do tambor do jongo, as rezas das ladainhas e das mesas de Santo, bem como a forma de cuidar da saúde através dos matos e das benzedeiras, são dimensões das memórias práticas que se mantêm na comunidade e orientam o processo de se aquilombar (Sá, 2007; 2013 ; 2016). As memórias práticas são transmitidas através das relações face-aface, através das memórias orais das pessoas mais velhas, assim como de memórias documentais, geralmente construídas através de agentes externos da comunidade (Sá, 2007; 2013; Silva, 2012).

Observamos que entre as moradoras mais antigas, há o esforço em transmitir e manter as memórias para as gerações mais novas, características das memórias étnicas e comunitárias (Sá, 2013). No entanto, notamos que, a partir da expropriação do território, esse modo de vida vem sendo alterado e existe uma preocupação das gerações mais velhas de que as práticas ancestrais e, consequentemente, a identidade quilombola se percam (Valentim, 2010; Valentim \& Trindade, 2011). A falta de terra causada pela vasta plantação de eucalipto tem dificultado a permanência do segmento juvenil na comunidade e consequente êxodo em busca de emprego e qualificação profissional em áreas urbanas. Nesse sentido, corroboramos com Leite (2000) ao afirmar que é impossível se falar de quilombos e de quilombolas atualmente no Brasil sem entendê-los como grupo em luta política pelo território. Portanto, a noção de territorialidade se mostra fundamental para a construção do sentimento de identidade entre as mulheres da comunidade, posto que ser quilombola está associado ao uso comum da terra, ao pertencimento àquela terra e às práticas que vem sendo transmitidas pelos antepassados (Ferreira, 2010; Oliveira, 2018). 
Em um contexto de disputa territorial com grandes empreendimentos agroindustriais (Leite, 2000; Ferreira, 2010; Valentim, 2010; Oliveira, 2011; Silva, 2012), os processos identitários e as memórias passam a ser disputados em conflitos sociais e intergrupais, principalmente, aqueles que opõem grupos políticos diversos (Pollak, 1992). Isso fica evidente nas disputas territoriais na comunidade, em que as memórias justificam a identidade quilombola, que, por sua vez, oferece aos moradores da comunidade o direito ao território que foi expropriado pelas empresas e fazendeiros. Entendemos que a partir do contato com grupos políticos e lideranças do movimento quilombola, as mulheres passaram a se comparar com outros grupos que possuem histórias e práticas semelhantes e reforçaram o seu auto-reconhecimento como quilombolas (Deschamps \& Moliner, 2008).

A partir da perspectiva psicossocial da memória social (Sá, 2007), é possível destacar a atuação da memória étnica no fenômeno em análise. Essa instância, segundo Sá (2013), engloba as memórias construídas na relação cotidiana e face a face de um grupo. Ou seja, a partir da memória oral e da memória prática, as memórias pessoais se confundem com a própria história do grupo, mesmo que as pessoas não tenham vivido os fatos históricos e sociais diretamente, configurando importante campo de significação que orienta os processos de identificação social. Conforme resultados encontrados, observamos o empenho das gerações mais velhas em produzir, conservar e transmitir as memórias do grupo às novas gerações (Valentim, 2010; Valentim \& Trindade, 2011), o que permite reformular e recontar a história do quilombo Sapê do Norte a partir do tempo vivido no presente (Jedlowski, 2003). As memórias étnicas ou comunitárias se materializam nas diferentes identidades, nos permitindo refletir sobre o caráter multidimensional, processual, situacional e relacional das identidades no trabalho cotidiano de [re]elaboração da vida social dos grupos humanos (Cuche, 2002; Deschamps \& Moliner, 2008; Bonomo, 2010).

\section{Considerações Finais}

O objetivo desse estudo consistiu em analisar, através da abordagem psicossocial da memória social, os processos identitários entre mulheres quilombolas de uma comunidade do Sapê do Norte, no estado do Espírito Santo, mediante a análise de suas narrativas sobre sua história e modo de vida. Conforme resultados encontrados, descrevemos as práticas sociais presentes no cotidiano, na vivência comunitária, nas relações de trabalho, nos processos educativos, nas festas, na religiosidade e na maneira de cuidar da saúde na 
comunidade. Verificamos que as mulheres compartilham memórias da luta e da resistência de seus antepassados contra a escravização e da expropriação do território a partir da década de 1960, principalmente, pelas empresas que fazem uso do sistema de plantation de eucalipto. A identidade quilombola entre as mulheres entrevistadas parece orientar-se, portanto, pelas memórias e modo de vida característico da comunidade, marcados por práticas, relações e formas de organização que rememoram seus antepassados e pelo uso comum da terra.

Considerando a perspectiva psicossocial do fenômeno da memória a partir da Psicologia Social, entre as possíveis contribuições do estudo, destaca-se a abordagem de instâncias complexas da memória, tal qual sugerida por Sá (2013), como a instância da memória étnica no contexto sociocultural quilombola. Através dessa ótica, podemos entender que as mulheres que entrevistamos são agricultoras, pescadoras, militantes, cozinheiras, benzedeiras, mães, zeladoras, referências familiares, conhecedoras dos saberes tradicionais, mestras do jongo, reis de bois, do beiju e da farinha, senhoras do dendê ao mesmo tempo em que sofrem pela falta de emprego, pela falta de território, pela fata de acesso a serviços públicos e pela falta de oportunidades, causadas principalmente pela expropriação do território (Ferreira, 2010; Silva, 2012; Oliveira, 2018). São protagonistas e empoderadas, têm seu valor reconhecido pelo grupo, mas também sofrem por estarem dentro de uma estrutura de gênero, classe e raça desigual (Riscado e outros, 2010; Grossi e outros, 2018). Essas ambiguidades se materializam nas memórias e no processo de aquilombar das mulheres (Pollak, 1992; Jedlowiski, 2003; Sá, 2007; 2013).

Sobre as possíveis limitações desse estudo, é importante ressaltar que a pesquisa se restringe a uma determinada comunidade quilombola da região do Sapê do Norte, e a um grupo de liderança feminina desse território, com características específicas. O estudo não representa, portanto, a multiplicidade de histórias, memórias e organizações de comunidades negras que resistiram ao processo de escravização no Brasil e no contexto local do estado do Espírito Santo. Entre questões que se configuram como tarefa para novos estudos, destacamos a necessidade de análise dos processos de identificação identitária entre as novas gerações, especialmente entre aqueles que vivenciaram o fenômeno do êxodo rural.

\section{Referências}

Bardin, L. (2004) Análise de Conteúdo (L. A. Reto \& A. Pinheiro, Trad.). (3a ed.). Lisboa: Edições 70. (Original publicado em 1977). 
Bartlett, F. C. (1995). Remembering: a study in experimental and social psychology. Cambridge: Cambridge University. (Original publicado em 1932).

Bonomo, M. (2010). Identidade social e Representações Sociais de rural e cidade em um contexto rural comunitário: campo de antinomias. Tese de Doutorado, Programa de Pós-Graduação em Psicologia, Universidade Federal do Espírito Santo, Vitória, ES.

Bosi, E. (1979). Memória e sociedade: lembranças dos velhos. São Paulo: T. A. Queiroz.

Bosi, E. (2003). O tempo vivo da memória: ensaios de psicologia social. São Paulo: Ateliê Editorial.

Bragas, J. \& Cal, D. G. R. (2018). Luta por reconhecimento, identidades e relações de poder: as mulheres quilombolas no movimento quilombola. Revista Observatório, 4(6), 475-505.

Caixeta, J. E. (2006). Guardiãs da memória: tecendo significações de si, suas fotografias e seus objetos. Tese de Doutorado, Instituto de Psicologia, Universidade de Brasília, Brasília, DF.

Costa, R. B. R. (2018). Um nome a zelar: História de uma quilombola do norte do Espírito Santo. Dissertação de Mestrado, Programa de Pós-Graduação em Ciências Sociais, Universidade Federal do Espírito Santo, Vitória, ES.

Cuche, D. (2002). A noção de cultura nas Ciências Sociais (V. Ribeiro, Trad.). (2a ed.). Bauru, SP: EDUSC. (Original publicado em 1999).

Deschamps, J. C. \& Moliner, P. (2009). A identidade em psicologia social: dos processos identitários às representações sociais. Petrópolis: Vozes.

Ferreira, S. R. B. (2010). Donos do Lugar: A Geo-grafia negra e camponesa do Sapê do Norte, ES. Revista Geografares, 8, 1-23.

Flick, U. (2013). Introdução à metodologia de pesquisa: um guia para iniciantes (M. Lopes, Trad.). Porto. Alegre: Penso. (Original publicado em 2013).

Grossi, P. K., Oliveira, S. B. \& Oliveira, J. L. (2018). Mulheres Quilombolas, Violência e as interseccionalidades de gênero, etnia, classe social e geração. Revista de Políticas Públicas, 22, 930-948.

Halbwachs, M. (1994). Les cadres sociaux de la mémoire. Paris: Albin Michel. (Original publicado em 1925).

Jedlowski, P. (2003). Memórias: temas e problemas da sociologia da memória do século XX. Pró-Posições, 14(1), 217-234. 
Leite, I. B. (2000). Os quilombos no Brasil: questões conceituais e normativas. Etnográfica, 4(2), 333-354.

Oliveira, D. C. (2008). Análise de Conteúdo Temático-Categorial: uma proposta de sistematização. Revista Enfermagem UERJ, 16(4), 569-576.

Oliveira, O. M. (2011). Comunidades Quilombolas no Estado do Espírito Santo: Conflitos sociais, consciência étnica e patrimônio cultural. Ruris, 5(2), 141171.

Oliveira, O. M. (2016). Quilombos e demarcadores de identidades: análise sucinta de três casos no estado de Espírito Santo. Revista do Grupo de Pesquisa Processos Identitários e Poder, 4(7), 10-41.

Oliveira, O. M. (2018). Congo: demarcador de identidade em uma comunidade quilombola. Revista do Arquivo Público do Estado do Espírito Santo, 3(2), 99-118.

Pollak, M. (1992). Memória e Identidade Social. Estudos Históricos, 5(10), 200212.

Rabinovich, E. P. (2008). O comum em uma comunidade quilombola baiana no século XXI e o terreiro de candomblé. Memorandum, 14, 86-102.

Riscado, J. L. S., Oliveira, M. A. B. \& Brito, A. M. B B. (2010). Vivenciando o racismo e a violência: um estudo sobre as vulnerabilidades da mulher negra e a busca de prevenção do HIV/aids em comunidades remanescentes de Quilombos, em Alagoas. Saúde e Sociedade, 19(2), 96108.

Rodrigues, L. H. (2016). Quilombolas e Jongueiros: Uma etnografia nas comunidades de Linharinho e Porto Grande, Conceição da Barra (ES). Dissertação de Mestrado, Programa de Pós-Graduação em Ciências Sociais da Universidade Federal do Espírito Santo, Vitória, ES.

Sá, C. P. (2007). Sobre o Campo de Estudo da memória Social: uma perspectiva psicossocial. Psicologia: Reflexão \& Crítica, 20(2), 290-295.

Sá, C. P. (2013). A Psicologia Social da Memória: Uma sistematização teóricoconceitual. Em C. P. Sá, P. R. M. Menandro \& L. A. M. Naiff (Orgs). Psicologia Social e o estudo da Memória Histórica (pp. 13-26). Curitiba: Appris.

Sá, C. P. (2016). Os níveis de explicação na Psicologia Social da Memória. Em D. X. França \& M. E. L. Lima (Orgs). Níveis de Análise e formas de intervenção em psicologia Social (pp. 75-86). São Paulo: Scortetti. 
Silva, L. A. (2015). O "alvoroço do mangangá". Uma análise do processo patrimonialista do jongo na comunidade de São Mateus, Anchieta (ES). Dissertação de Mestrado, Programa de Pós-Graduação em Ciências Sociais, Universidade Federal do Espírito Santo, Vitória, ES.

Silva, S. J. (2012). Do fundo daqui: Luta política e identidade quilombola no Espírito Santo. Tese de Doutorado, Programa de Pós-Graduação em Antropologia, Instituto de Filosofia e Ciências Humanas, Universidade Federal Fluminense, Niterói, RJ.

Siqueira, J. (2017). "Se o mestre não tiver firmação ele vai a nado": o Jongo de São Bartolomeu no norte capixaba. Dissertação de Mestrado, Programa de Pós-Graduação em Ciências Sociais, Universidade Federal do Espírito Santo, Vitória, ES.

Turner, J. C. (1984). Social identification and psychological group formation. Em H. Tajfel (Org.). The social dimension (Vol. 1, pp. 519-538). Cambridge/Paris: Cambridge University Press / Édition de la Maison des Sciences de I'Homme.

Valentim, R. P. F. (2010). Os três tempos da memória: Aspectos Psicossociais da memória social entre quilombolas do Norte do Espírito Santo. Tese de Doutorado, Programa de Pós-Graduação em Psicologia, Universidade Federal do Espírito Santo, Vitória, ES.

Valentim, R. P. F. \& Trindade, Z. A. (2011). Modernidade e comunidades tradicionais: memória, identidade e transmissão em território quilombola. Revista Psicologia Política, 11(22), 295-308.

\section{Nota sobre os autores:}

Pedro Henrique Barbosa de Souza é psicólogo. Mestre em Psicologia pelo Programa de Pós-Graduação em Psicologia da Universidade Federal do Espírito Santo. E-mail: pedrobs.psi@gmail.com.

Mariana Bonomo é professora do Departamento de Psicologia Social e do Desenvolvimento, Universidade Federal do Espírito Santo. E-mail: marianadalbo@gmail.com.

Data de submissão: 16.04 .2020

Data de aceite: 13.01.2021 